\title{
Correction to: Downregulation of miR-223 promotes HMGB2 expression and induces oxidative stress to activate JNK and promote autophagy in an in vitro model of acute lung injury
}

Hao-Yu Tan' ${ }^{1}$ Bei Qing², Xian-Mei Luo ${ }^{2}$ and Heng-Xing Liang ${ }^{2^{*}}$

Correction to: J Inflamm 18, 29 (2021). https://doi.org/10.1186/s12950-021-00295-3

Following publication of the original article [1], it was reported that there was an error in the affiliations. Affiliation 1 was erroneously assigned to all authors instead of only to Hao-Yu Tan.

The correct affiliation information is given in this Correction and the original article [1] has been updated.

\begin{abstract}
Author details
'Department of Cardio-vascular Surgery, the Second Xiangya Hospital of Central South University, No.139 Middle Renmin Road, Hunan Province 410011 Changsha, People's Republic of China. ${ }^{2}$ Department of Thoracic Surgery, the Second Xiangya Hospital of Central South University, No.139 Middle Renmin Road, Hunan Province 410011 Changsha, People's Republic of China.
\end{abstract}

Published online: 07 December 2021

\section{Reference}

1. Tan HY, Qing B, Luo XM, Liang HX. Downregulation of miR-223 promotes HMGB2 expression and induces oxidative stress to activate JNK and promote autophagy in an in vitro model of acute lung injury. J Inflamm. 2021;18(1):29. https://doi.org/10.1186/s12950-021-00295-3.

The original article can be found online at https://doi.org/10.1186/s12950021-00295-3.

* Correspondence: lianghengxing84@csu.edu.cn

${ }^{2}$ Department of Thoracic Surgery, the Second Xiangya Hospital of Central South University, No.139 Middle Renmin Road, Hunan Province 410011

Changsha, People's Republic of China

C C The Author(s). 2021 Open Access This article is licensed under a Creative Commons Attribution 4.0 International License, which permits use, sharing, adaptation, distribution and reproduction in any medium or format, as long as you give appropriate credit to the original author(s) and the source, provide a link to the Creative Commons licence, and indicate if changes were made. The images or other third party material in this article are included in the article's Creative Commons licence, unless indicated otherwise in a credit line to the material. If material is not included in the article's Creative Commons licence and your intended use is not permitted by statutory regulation or exceeds the permitted use, you will need to obtain permission directly from the copyright holder. To view a copy of this licence, visit http://creativecommons.org/licenses/by/4.0/. The Creative Commons Public Domain Dedication waiver (http://creativecommons.org/publicdomain/zero/1.0/) applies to the data made available in this article, unless otherwise stated in a credit line to the data. 